\title{
Therapeutic alliance in the initial phase of psychotherapy with adolescents: different perspectives and their association with therapeutic outcomes
}

\author{
Olga María Fernández, ${ }^{1}$ Mariane Krause, ${ }^{2}$ Janet Carola Pérez ${ }^{3}$ \\ ${ }^{1}$ Millennium Institute for Research in Depression and Personality, University of Chile, Santiago; ${ }^{2}$ Millennium Institute for Research in \\ Depression and Personality, Catholic University of Chile, Santiago; ${ }^{3}$ Millennium Institute for Research in Depression and Personality, \\ University of Development, Santiago, Chile
}

\begin{abstract}
Psychotherapy research focusing on adults as well as on children and adolescents has revealed a positive association between the quality of the therapeutic alliance (TA) in the first sessions and therapeutic outcomes. Nevertheless, there is controversy regarding which perspective (of the adolescents, therapists, or parents) and what moment of evaluation (first, second, or third session) is most strongly associated with outcome. This study aims to describe the TA during the initial phase of psychotherapy with adolescents, from several perspectives, and relate it to the intermediate and final outcomes of the therapy. The study is descriptive-correlational and was conducted in naturalistic settings. The sample comprised 20 individual psychotherapeutic processes ( 15 females, 5 males; average age: 15.8 years; standard deviation=1.04). The variables studied were: TA, measured with the Working Alliance Inventory, applied to adolescents, therapists, and parents, and therapeutic outcomes, measured using Lambert's Outcome Questionnaire (OQ- 45.2). The results show that the TA improved from session one to session three, both in the adolescents and the therapists. The TA, as perceived by the adolescents in the third session, is positively correlated with final outcomes $(\mathrm{r}=-.732 *, \mathrm{P}=.025)$. The TA evaluated from the therapists' perspective in the third session, specifically the bond component of the TA, predicts the final success of psychotherapy with adolescent patients $[\beta=0.426$, Exp. $(B)=1.531$, degree of freedom $=1, P=0.034]$. The importance of the initial construction of the working alliance by both participants is discussed.
\end{abstract}

Key words: Psychotherapy with adolescents; Therapeutic alliance in the initial phase; Therapeutic outcomes.

Correspondence: Olga María Fernández, Millennium Institute for Research in Depression and Personality, University of Chile, Av Libertador Bernardo O'Higgins 1058, Santiago, Chile.

Tel: +56.2 .3545980 .

E-mail: mofernandez36@gmail.com

Acknowledgments: this study was supported by the Fund for Innovation and Competitiveness (FIC) of the Chilean Ministry of Economy, Development, and Tourism, through the Millennium Scientific Initiative, Grant $\mathrm{N}^{\circ}$ IS130005 and the National Research and Technology Commission (FONDECYT), Grant \#11130041. Additionally, we thank FONDECYT, which funded the doctoral studies of the first author.

Citation: Fernandez, O.M., Krause, M., \& Pérez, J.C. (2016). Therapeutic alliance in the initial phase of psychotherapy with adolescents: different perspectives and their association with therapeutic outcomes. Research in Psychotherapy: Psychopathology, Process and Outcome, 19(1), 1-9. doi: 10.4081/ripppo.2016.180

Received for publication: 14 July 2015.

Accepted for publication: 17 December 2015.

This work is licensed under a Creative Commons Attribution NonCommercial 4.0 License (CC BY-NC 4.0).

CCopyright O.M. Fernandez et al., 2016

Licensee PAGEPress, Italy

Research in Psychotherapy:

Psychopathology, Process and Outcome 2016; 19:1-9

doi:10.4081/ripppo.2016.180

\section{Introduction}

The initial phase of therapy is regarded as a key moment for the successful completion of the process (Hill, 2005; Howard, Lueger, Maling, \& Martinovich, 1993; Krause, 2005; Oddli \& Halvorsen, 2014; Oddli \& Rønnestad 2012; Prochaska \& DiClemente, 1983), which is true of psychotherapy for both adults (Alberti, Martorano, \& Martorano, 2013) and adolescents (Oetzel, \& Scherer, 2003; Thompson, Bender, Lantry, \& Flynn, 2007). However, this is especially important in the case of the latter, because evidence indicates that adolescents experience difficulties in the establishment of the helping relationship and that they abandon their treatment during the initial sessions (Baruch, Gerber, \& Fearon, 1998; Bronstein \& Flanders, 1998; Kazdin, 1990; Manríquez, Molina, \& Zubarew, 2003; Martínez, Martínez, Poblete, Chang, Brand, \& Soto, 2009; Scheffler, 2002). In this regard, it has been advanced that adolescents who receive treatment tend to do so motivated by others (parents, family, and/or school), because they often fail to perceive the dysfunctionality of their behavior, which hinders permanence in the treatment and affects therapeutic outcomes (Kazdin, 2004). In addition, the typical characteristics of this age group, such as the need for autonomy, self-determination, self-affimation, and mistrust of adult authority (Russell, Shirk, \& Jungbluth, 2008), 
along with adolescents' level of formal operational cognitive development (Coll, Palacios, \& Marchesi, 2004), lead them to relativize adults' opinions, de-idealizing or devaluing their contribution.

\section{Therapeutic alliance and psychotherapeutic outcomes}

Although different definitions of therapeutic alliance (TA) exist in the field of psychotherapy research, the scientific consensus is that the alliance captures the collaborative element in the patient-therapist relationship, taking into account the patient's and the therapist's ability to negotiate a contract that suits the scope and the depth of the therapy (Horvath \& Symonds, 1991; Santibáñez, 2002). Bordin (1976) conceptually organizes the notion of TA by including three aspects: i) establishment and development of the bond; ii) agreement on the goals or objectives of the therapeutic process; and iii) agreements about tasks and responsibilities for attaining those goals. The tasks are the actions and thoughts that comprise the work done during the therapeutic process, so that perceiving these actions or tasks as relevant for improvement is important for the establishment of the alliance. In addition, the existence of an agreement between the therapist and the patient regarding the objectives of the psychotherapy, along with having a relationship characterized by trust and acceptance, are key elements for a good alliance (Corbella \& Botella, 2003). These three levels have been studied in terms of their contribution to the TA (Horvath \& Greenberg, 1986).

Psychotherapy research has identified TA as a central and generic factor of change (Lambert, 1992; Orlinsky \& Howard, 1986). Studies on psychotherapy effectiveness and the factors associated with therapeutic outcomes have concluded that the therapeutic relationship and TA explain therapeutic outcomes to a large extent. In fact, the therapeutic relation accounts for $30 \%$ of patient improvement (Lambert \& Barley, 2002), and the therapeutic alliance explains between 25 and $30 \%$ of the variance of therapeutic outcomes (Horvath, Del Re, Flückiger, \& Symonds, 2011).

Although there is consistent evidence that links TA and psychotherapeutic outcomes, it is still unclear how the former affects the latter. A study by Alberti, Martorano, \& Martonano (2013) evaluated the relationship between TA and change, exploring variables thought to act as moderators in the TA-outcomes association (Kazdin, 2004). These authors note that the level of depressive symptomatology affects the formation of initial TA and its predictive value with respect to outcomes. Another study (Oddli \& Halvorsen, 2014) suggests those therapists' skills for constructing initial TA, specifically the methods and/or strategies used, act as moderators in the TA-outcomes relationship. On the other hand, Hoffart, Borge, Sexton, Clark, \& Wampold (2012), from a cognitive perspective, advance two mechanisms through which the TA effects change. One of them is direct, based on the notion that the therapeutic relationship is therapeutic in itself and that agreement on the therapy's tasks and goals makes the patient accept the explanations to his/her problem, increases his/motivation to complete tasks, and boosts his/her expectations of self-efficacy and re-moralization which reduces the extent of his/her problem and leads to better results. The indirect mechanism that the authors advance is that the alliance acts as a facilitator of changes inasmuch as it combats or questions the factors that sustain the disease or problem. By following the treatment indications, the mistaken cognitions that support the problem start losing strength, which fosters the emergence of new cognitions and behaviors.

Psychotherapy research in general - in both the common factors and process-outcome approaches - has focused on adults to the detriment of children and adolescents (Russell, 2008). Specifically in psychotherapy with adolescents, the association between the TA and outcomes has received considerably less attention than in psychotherapy with adults (Green, 2006). However, consistent evidence exists linking the TA with treatment outcomes, both in children and adolescents (Martin, Garske, \& Davies, 2000; Shirk \& Karver, 2003; Russell et al., 2008). Studies have shown that the time shared, openness, role differentiation, guidance, identification, and familiarity with the therapist foster patients' trust in the treatment and their commitment to it (Martin, Romas, Medford, Leffert \& Hatcher, 2006). Shirk \& Karver (2003) conducted a meta-analysis of 23 studies that linked the TA and treatment outcomes in children and adolescents in order to evaluate the presence of moderating factors in this association. Their results indicated that the most significant moderators in the alliance-outcomes association are the patient's type of problem, the moment of evaluation of the alliance, the person who reports the alliance, and the type of measurement of the outcome. Other criteria that were evaluated and were not found to be significant moderators in the alliance-outcomes association were the patient's age, the type of therapy (behavioral: cognitive behavioral therapy, skills training, parents training; non-behavioral: psychodynamic, client-centered, and eclectic), the mode of therapy (individual, family, or parentsonly), the structure of the therapy (manualized vs non-manualized), and the context of the therapy (health care center and research context).

The following is a review of studies, which have examined the relation between different evaluations of the TA and therapeutic outcomes, as well as the association between the moment of the process during which the TA was assessed and final therapeutic results.

\section{Perspectives and moments of evaluation in the relation of the therapeutic alliance with therapeutic outcomes}

The issue of the perspective of the alliance (patient or therapist) and the moment in which it is evaluated has not been conclusively solved and is still being debated in the field of psychotherapy with adolescents. In psychotherapy with adults, evidence indicates that the quality of the alliance as evaluated by the patient is more closely con- 
nected with therapeutic outcomes than the quality of the alliance as evaluated by the therapist (Orlinsky, Ronnestad, \& Willutzky, 2004). This is not the case for studies with adolescents, where information about which view of the alliance is more strongly related to outcomes (the adolescent's, the therapist's, the parents', or an observer's) seems to be contradictory (Fenton, Cecero, Nich, Frankforter, \& Carroll, 2001; Shelef, Diamond, Diamond, \& Liddle, 2005). On the other hand, a meta-analysis by Shirk \& Karver (2003) indicates that the evaluations by the therapist display a stronger association than those by the patients, because the latter were less variable and tended to be very positive. Some years later, Karver et al. (2008) stated that the alliance as evaluated by the adolescent displays the strongest association with therapeutic outcomes, but that this link was moderated by the adolescent's involvement in his/her treatment.

In addition, it has been suggested that the participation of other family members in the therapeutic process - as is common in therapy with children and adolescents - increases the complexity of the alliance issue. Some studies (Diamond, Diamond, \& Liddle, 2000) indicate that the therapist's alliance with the parents is also related to therapeutic outcomes. Finally, Karver et al. (2008) pose that it is fundamental for studies to simultaneously consider the perspectives of the patient, the therapist, and an observer of the therapeutic interaction in order to compare them.

Regarding the moment of the therapy during which the alliance is evaluated, studies on therapy with children and adolescents (Bickman et al., 2004; Meier, Barrowclough, \& Donmall, 2005) indicate that the early TA predicts treatment outcomes in a wide range of therapeutic models and clinical populations, and that it is a better predictor than the TA in the middle of the therapy or its average throughout the treatment. With respect to the session during which the TA is evaluated in the initial phase and its association with outcomes, it has been reported that the TA level in the third session is the strongest predictor of treatment outcomes in psychotherapy with adolescents (Karver et al., 2008; O’Malley, Such, \& Strupp, 1983).

Therefore, the objective of this study is to describe the evaluation of the TA at three points of the initial phase (sessions 1, 2, and 3), considering several perspectives (adolescents, therapists, and parents) and connecting them with intermediate and final therapeutic outcomes. Specifically, the hypothesis is that the TA will increase from session 1 to 3 , both in patients and in therapists, and that the TA as evaluated by the adolescents will be more strongly related to final outcomes than the therapists' and the parents' evaluations.

\section{Methods}

\section{Participants}

The participants were 20 adolescents receiving individual therapy in an outpatient center; 15 were female and
5 male, aged 15.9 years on average [standard deviation $(\mathrm{SD})=1.07$; range 13 to 17 years]. A comparison between the male and the female adolescents in the sample revealed no significant differences by age or by type of diagnosis, comparing anxious-depressive disorders with other disorders [Fischer's exact test $\mathrm{P}=0.62$ (2-tailed)]. Initial outcomes $[\mathrm{t}(18)=0.81, \mathrm{P}=.43]$ did not vary according to the participants' sex either; however, the intermediate and final OQ results could not be compared because there was only one male participant. No significant differences in TA levels were observed in association with gender, except for the TA of the female adolescents in the first measurement, which was reported to be higher by the female patients $[\mathrm{t}(18)=2.53 \mathrm{P} \leq .05]$ and by the therapists [ $\mathrm{t}(17)=2.39, \mathrm{P} \leq .05]$.

The adolescents were referred to psychological care from: psychiatry $(n=11)$, the school system $(n=4)$, their family $(\mathrm{n}=3)$, and spontaneously $(\mathrm{n}=2)$. The disorders noted in their medical records were: depressive disorders $(n=8)$, anxious disorders $(\mathrm{n}=3)$, behavioral disorders $(\mathrm{n}=3)$, adaptive disorders $(\mathrm{n}=5)$, and mood disorders $(\mathrm{n}=1)$.

On average, the 20 therapies lasted 4.65 months $(\mathrm{SD}=2.85)$ and comprised 15.15 sessions $(\mathrm{SD}=10.9)$. Table 1 shows the data for each therapy, including the number of sessions and the outcome measurements of each process. The sessions were programmed weekly, although this frequency was sometimes reduced because the adolescents rescheduled their appointments.

The therapies had different theoretical approaches: systemic/constructivist $(n=13)$, psychodynamic $(n=5)$, and cognitive-behavioral $(n=2)$. Eight therapists conducted the therapies (seven women and one man), whose average age was 34.6 years $(\mathrm{SD}=7.3)$; they had an average of 9.4 years $(\mathrm{SD}=4.3)$ of experience in psychotherapy. The sample was collected over a 34-month period.

\section{Variables and instruments}

\section{Therapeutic alliance}

According to Bordin's theory, the TA is regarded as the matching of the client's and the therapist's collaboration, with its three components: bond, tasks, and goals. The Working Alliance Inventory (WAI) by Horvath \& Greenberg (1986) was developed upon the basis of this theory.

The WAI has two versions: one for therapists (WAI-T) and another for patients (WAI-P); it comprises 36 items divided into three subscales of 12 items each (bond, goals, and tasks) which are scored using 7-point Likert-type scale. Both versions of the questionnaire have been translated, adapted, and validated in Chile by Santibáñez (2001), with reliability coefficients for the therapist version reaching $0.67,0.80,0.78$, and 0.93 for the bond, tasks, and goals subscales and for the total, respectively; on the other hand, the patient version reached $0.70,0.85$, 0.88 , and 0.90 for the bond, tasks, and goals subscales and for the total, respectively. The maximum possible score 
in each scale is 84 , whereas the minimum score is 12 . The maximum score for the total inventory is 252 , with a minimum of 36 . In the present study, the quality of the alliance was evaluated from the perspective of the adolescent, the therapist, and one of the parents, using the WAI (Horvath \& Greenberg, 1986). The questionnaire was applied in the first three sessions, immediately after they were conducted.

\section{Therapeutic outcomes}

In the present study, therapeutic outcomes will be understood as changes in the adolescent's psychological well being, evaluated pre- and post-therapy with the Outcome Questionnaire (OQ-45.2; Lambert et al., 1996; De la Parra, von Bergen \& del Río, 2002). This instrument was developed, validated, and widely used in the United States; it is characterized by its sensitiveness to change, which has been demonstrated in a number of countries. The OQ-45.2 was adapted and validated in Chile (de la Parra, von Bergen, \& del Río, 2002; von
Bergen, 2000) in a mid-low and low-SES population, aged between 15 and 60 years. Its test-retest reliability reached 0.9 , with an internal consistency of 0.91 . In addition, it was shown to have concurrent validity (Pearson product-moment correlation coefficient 0.60 and 0.76 ) with an instrument that measures symptomatology. The instrument comprises 45 items that evaluate three dimensions - symptom distress, interpersonal relations, and social role - and provides a score for each dimension and a total score. Each item is scored on an ordinal level Likert scale from 0 to 4 points. The score is obtained by adding up the score for each item. The result obtained indicates the patient's level of psychological wellbeing, but in an inverse fashion: that is, the higher the score, the lower the psychological wellbeing. The instrument provides a Reliable Change Index (RCI), which indicates the difference between the initial and final levels of psychological wellbeing. In the validation and standardization process conducted in Chile, the RCI was set at 17 points. In the present study, a therapy will be considered to be successful if the patient's RCI is equal to

Table 1. Description of the sample.

\begin{tabular}{|c|c|c|c|c|c|c|c|c|c|c|}
\hline \multicolumn{4}{|c|}{ Adolescent } & \multicolumn{4}{|c|}{ Therapy } & \multicolumn{3}{|c|}{ OQ-45.2 } \\
\hline ID & Age & Sex & Diagnosis & $\begin{array}{c}\text { Number of } \\
\text { sessions }\end{array}$ & $\begin{array}{l}\text { Theoretical } \\
\text { approach }\end{array}$ & $\begin{array}{c}\text { Therapist's } \\
\text { xperience (years) }\end{array}$ & Success & Initial & $6^{\text {th }}$ session & Final \\
\hline I & 17 & $\mathrm{~F}$ & Adaptive disorders & 7 & Systemic/constructivist & 3 & Success & 51 & 32 & 12 \\
\hline II & 17 & $\mathrm{~F}$ & Behavioral disorders & 3 & Systemic/constructivist & 9 & No success & 84 & - & - \\
\hline III & 15 & M & Behavioral disorders & 3 & Systemic/constructivist & 9 & No success & 65 & - & - \\
\hline IV & 15 & $\mathrm{~F}$ & Adaptive disorders & 26 & Systemic/constructivist & 9 & Success & 78 & 85 & 46 \\
\hline $\mathrm{V}$ & 16 & $\mathrm{~F}$ & Depressive disorders & 20 & Psychodynamic & 10 & Success & 76 & 71 & 33 \\
\hline VI & 17 & $\mathrm{~F}$ & Anxious disorders & 14 & Systemic/constructivist & 8 & No success & 24 & 32 & 19 \\
\hline VII & 17 & $\mathrm{~F}$ & Anxious disorders & 30 & Systemic/constructivist & 9 & Success & 73 & 74 & 19 \\
\hline VIII & 13 & $\mathrm{~F}$ & Anxious disorders & 1 & Systemic/constructivist & 8 & No success & 63 & - & - \\
\hline IX & 16 & $\mathrm{~F}$ & Depressive disorders & 8 & Systemic/constructivist & 9 & Success & 116 & 96 & - \\
\hline $\mathrm{X}$ & 16 & $\mathrm{~F}$ & Adaptive disorders & 34 & Psychodynamic & 10 & No success & 41 & 55 & 61 \\
\hline $\mathrm{XI}$ & 16 & $\mathrm{~F}$ & Depressive disorders & 10 & Psychodynamic & 10 & Success & 85 & 40 & - \\
\hline XII & 17 & $\mathrm{~F}$ & Depressive disorders & 16 & Psychodynamic & 10 & No success & 96 & 99 & - \\
\hline XIII & 15 & M & Depressive disorders & 16 & Systemic/constructivist & 8 & No success & 75 & 97 & 65 \\
\hline XIV & 16 & $\mathrm{~F}$ & Adaptive disorders & 15 & Psychodynamic & 10 & No success & 65 & 75 & 55 \\
\hline $\mathrm{XV}$ & 15 & $\mathrm{~F}$ & Depressive disorders & 31 & Systemic/constructivist & 8 & No success & 90 & 99 & 82 \\
\hline XVI & 15 & M & Behavioral disorders & 12 & Systemic/constructivist & 8 & No success & 71 & - & - \\
\hline XVII & 16 & M & Depressive disorders & 6 & Cognitive behavioral therapy & 18 & No success & 85 & - & - \\
\hline XVIII & 17 & $\mathrm{~F}$ & Depressive disorders & 34 & Cognitive behavioral therapy & 18 & Success & 100 & 95 & 60 \\
\hline XIX & 17 & M & Adaptive disorders & 1 & Systemic/constructivist & 12 & No success & 22 & - & - \\
\hline XX & 15 & $\mathrm{~F}$ & Mood disorders & 16 & Systemic/constructivist & 18 & Success & 61 & 43 & 27 \\
\hline
\end{tabular}

OQ-45.2, Lambert's Outcome Questionnaire. 
or higher than 17 points; in contrast, a therapy will be regarded as unsuccessful when the patient's RCI is lower than 17 points on the OQ-45.2.

\section{Procedures}

Three Santiago de Chile-based institutions were contacted, all of which provide individual psychological care to adolescents employing various theoretical approaches. This meant that the therapies studied were conducted in a naturalistic context and that the sample was heterogeneous. The institutions were selected purposively and following an accessibility criterion. The therapists, the patients, and their parents gave their assent and/or consent in writing for the three initial sessions to be video recorded and for filling in the questionnaires. The study was approved by the Ethics Committee in the School of Psychology at the Pontificia Universidad Católica de Chile, Santiago, Chile.

The psychotherapy appointment data at the participating institutions were reviewed weekly to find out whether any of the adolescents being treated met the inclusion criteria. The inclusion criteria were: adolescents between 14 and 18 years of age, male or female, who were starting an individual therapy process when recruited. The exclusion criteria were mental retardation, a diagnosis of general developmental disorder, or psychosis. Once the parents and the adolescents agreed to participate, they were requested to read and sign the informed assent and consent forms for the first three sessions to be video recorded and for completing the questionnaires. Both the patient and the therapist completed the WAI immediately after each of the first three sessions. Also, if one of the parents took part in any of these sessions, he/she also completed the WAI. After the beginning of the first, sixth, and final sessions, the adolescents had to take the OQ-45.2. The data regarding the diagnosis, source of referral, and number of sessions at- tended were later requested from the psychologist conducting the treatment.

\section{Results}

\section{Analysis of the alliance in the initial phase of psychotherapy with adolescents, from different perspectives and at different moments}

The first step was to conduct a descriptive analysis of TA behavior in the three initial sessions, in order to describe and compare the quality of the TA according to the perspectives of the participants (adolescents, therapists, and parents) and at three moments of the initial phase (sessions one, two, and three). These analyses were carried out using repeated measures ANOVA. The repeated measures analyses carried out do not consider the parents' evaluations, because they only completed the WAI in the session that they attended during the initial phase.

A significant effect was found for the time variable, $F(2,26)=3.66 ; \mathrm{P}<.05 ; \eta^{2}=0.22$ in patients, and therapists, $F(2,24)=6.88 ; \mathrm{P}<.01 ; \eta^{2}=.36$. Planned comparisons indicate that statistical differences were present in the average TA between sessions 1 and 3 as evaluated by patients $\left[F(1,13)=5.72 ; \mathrm{P}<.05 ; \eta^{2}=0.31\right]$ and therapists $[F(1$, $\left.12)=10.68 ; \mathrm{P}<.01 ; \eta^{2}=.47\right]$. Differences in the evaluation of the TA between sessions 2 and 3 were non-significant both in patients and in therapists.

When comparing the averages of the TA subscales (bond, tasks, and goals), it can be observed that the differences between sessions 1 and 3 are present in all subscales in the case of the therapists [bond, $F(1$, $12)=5.31 ; \mathrm{P}<.05$, tasks, $F(1,12)=9.62 ; \mathrm{P}<.01$, and goals, $F(1,12)=12.88 ; \mathrm{P}<.01]$. In the case of the adolescents, these differences affect the bond $[F(1,13)=5.13 ; \mathrm{P}<.05]$ and tasks $[F(1,13)=13.22 ; \mathrm{P}<.01]$ subscales (Table 2$)$. Regarding the comparison of the TA in the second and

Table 2. Means and standard deviations of the therapeutic alliance evaluations by adolescents and therapists in sessions 1,2 , and 3.

\begin{tabular}{|c|c|c|c|c|c|c|c|c|c|}
\hline & \multirow[b]{2}{*}{$\mathbf{N}$} & \multicolumn{2}{|c|}{ Bond } & \multicolumn{2}{|c|}{ Goals } & \multicolumn{2}{|c|}{ Tasks } & \multicolumn{2}{|c|}{ Total } \\
\hline & & Mean & SD & Mean & SD & Mean & SD & Mean & SD \\
\hline \multicolumn{10}{|c|}{ Adolescents } \\
\hline Session 1 & 14 & $69.98 *$ & 14.54 & 68.86 & 11.49 & $72.36^{* *}$ & 10.33 & $211.19 *$ & 33.289 \\
\hline Session 2 & 14 & 71.43 & 11.26 & 71.57 & 7.45 & 74.5 & 7.60 & 217.5 & 24.716 \\
\hline Session 3 & 14 & $75.14^{*}$ & 9.08 & 71.43 & 8.75 & $76.64 * *$ & 8.64 & $223.21 *$ & 24.696 \\
\hline \multicolumn{10}{|l|}{ Therapist } \\
\hline Session 1 & 13 & $74.15^{*}$ & 6.58 & $69.23 * *$ & 7.95 & $70.92 * *$ & 6.83 & $214.31 * *$ & 20.147 \\
\hline Session 2 & 13 & 76.62 & 4.94 & 71.69 & 5.68 & 74.31 & 4.40 & 222.62 & 13.961 \\
\hline Session 3 & 13 & $78.46^{*}$ & 3.71 & $74.54 * *$ & 5.58 & $76.31^{* *}$ & 5.94 & $229.31 * *$ & 12.854 \\
\hline
\end{tabular}

$\mathrm{SD}$, standard deviation. ${ }^{*} \mathrm{P} \leq .05 ; * * \mathrm{P} \leq .01$. 
third sessions, no significant differences were found, except for the bond subscale, were only the adolescents report differences between these sessions [F (1, 13) $=16.01 ; \mathrm{P}<.01]$.

When comparing the evaluation of the TA from the perspective of adolescents and therapists, no significant differences were observed between the three initial sessions $[\lambda=.96, F(3,23)=.31, \mathrm{P}=.32]$.

Regarding the TA as evaluated by the parents, it must be noted that, out of the 20 therapeutic processes studied, only 15 involved the participation of the parents (mother, father, or both) in at least one of the sessions with their children. The TA of the three individuals (parents, adolescents, and therapists) who participated in the session was considered, and a comparison between their averages was performed. The parents' evaluation of the TA ( $M=218.47$, $\mathrm{SD}=22.65)$ did not display significant differences with that of their adolescent sons or daughters $(M=216.80$, $\mathrm{SD}=22.67)[t(14)=0.485, \mathrm{P}=0.762]$ or of the therapists $[(M=215.67, \mathrm{SD}=13.42): t(14)=0.485, \mathrm{P}=0.635]$ in the same session.

In brief, the TA in the initial phase of psychotherapy with adolescents is characterized by a lack of significant differences between the evaluations conducted by patients, therapists, and parents. In addition, both in patients and therapists, the alliance displayed a positive evolution when comparing the first and the third sessions.

\section{Therapeutic alliance and its connection with psychotherapeutic outcomes}

Before establishing the association between the TA and outcomes, the potential impact of the variables (therapist's years of experience) and (number of sessions attended) on the TA and outcomes was analyzed. The variable number of sessions showed a correlation with TA as perceived by the patient $\left(2^{\text {th }}\right.$ session $\mathrm{r}=.56, \mathrm{P}=.018 ; 3^{\text {rd }}$ session $\mathrm{r}=.54, \mathrm{P}=.036$ ).

Partial correlation analyses were conducted considering the TA perceived by patients and therapists in the three initial sessions as well as the intermediate outcomes (sixth session) and the final outcomes, controlling for the number of sessions. In the case of the adolescents, the results indicated that the TA perceived in the second and third session is significantly and inversely correlated with the final OQ-45.2 score (Table 3). In the case of the therapists, the TA as evaluated in the first and the second session is significantly and directly correlated with the intermediate outcome (sixth session), but the evaluation of the TA in the third session was not significantly correlated with the final outcome. The TA as evaluated by the parents did not significantly correlate with the therapeutic outcomes evaluated by the OQ-45.2, either in the sixth $(r=.66, \mathrm{P}=.16)$ or the final sessions $(r=.27, \mathrm{P}=.61)$.

Finally, the therapies were classified according to the Reliable Change Index (17-point difference between the initial and the final evaluation) in successful (1) and unsuccessful therapies (0), and a logistic regression was carried out to determine the probability of success using TA scores as predictors. A comparison between the adolescents whose psychotherapeutic processes were successful and those whose processes were unsuccessful revealed no significant differences by sex (Fischer's exact test $\mathrm{P} \leq 0.55$ ) or age $(Z=0.608, P \leq 0.543)$. Significant differences were observed between successful and unsuccessful processes in terms of the therapists' years of experience $[t=11.731$, degree of freedom $(\mathrm{df})=19, \mathrm{P} \leq 0.000]$ and the number of sessions attended $(t=6.122, \mathrm{df}=19, \mathrm{P} \leq 0.000)$, with successful therapies being conducted by more experienced therapists and lasting longer.

A regression analysis was conducted using the TA quality scores reported by adolescents and therapists in sessions 1 and 3. Only the results of the regression model from the perspective of the therapists in the third session, specifically in the bond subscale, predicted the likelihood of success in psychotherapy with adolescents $[\beta=.45$, Exp. $(B)=1.57, \mathrm{df}=1, \mathrm{P} \leq .05]$, when controlling for the number of sessions attended. Thus, each additional point in the TA bond scale increases the probability of therapeutic success 1.57 times.

Table 3. Correlations between the therapeutic alliance of adolescents and therapists, and final and intermediate outcomes.

\begin{tabular}{lccccc}
\hline Patients & \multicolumn{3}{c}{ Therapists } \\
\cline { 2 - 6 } & TA session 1 & TA session 2 & TA session 3 & OQ session 6 & OQ final session \\
\hline TA session 1 & - & $.714^{* *}$ & .474 & $.883^{* * *}$ & .440 \\
\hline TA session 2 & $.821^{* * *}$ & & .440 & $.751^{* *}$ & .485 \\
\hline TA session 3 & $.816^{* * *}$ & $.799^{* * *}$ & & .160 & -.306 \\
\hline OQ session 6 & .011 & -.163 & -.395 & $.745^{*}$ \\
\hline OQ final session & -.558 & $-.983^{* * *}$ & $-.999^{* * *}$ & $0.768^{* *}$ & - \\
\hline
\end{tabular}

TA, therapeutic alliance; OQ, outcome questionnaire. The adolescent TA correlations with outcomes are presented below the diagonal, and the therapist TA correlations with outcomes are presented above the diagonal. $* \mathrm{P} \leq .05 ; * * \mathrm{P} \leq .01 ; * * * \mathrm{P} \leq .001$. 


\section{Discussion}

The results reported in the present study indicate that the TA in the initial phase of psychotherapy with adolescents was evaluated similarly by patients, therapists, and parents. Both in patients and therapists, the alliance displayed a significant (positive) evolution from session 1 to session 3. Early TA, as evaluated by adolescents and therapists but not by parents, displayed a significant association with the outcome of the process. This association displays some differences depending on the moment in which it is evaluated and on who evaluates the TA (the adolescent or the therapist), which constitutes a relevant discussion topic.

The TA from the adolescents' perspective, evaluated in the second and third session, is positively correlated with the final outcomes. The TA evaluated by the therapists in the first and second session is correlated with intermediate outcomes (session six), while the bond subscale in the third session predicts the final success of the therapy with adolescent patients. These differences in the correlations with intermediate and final outcomes, even though the average evaluations of the TA according to the patients and the therapists do not differ, might suggest that the score assigned by each of the participants does not refer to exactly the same construct; in the case of the patient it could be a self-reported alliance, while in the case of the therapist it is a clinician-reported alliance. In fact, the latter may respond based on his/her professional role and not considering his/her subjective experience of the alliance. In addition, it is necessary to bear in mind that the WAI was essentially created for the patient and later adapted for the therapist.

On the other hand, in adolescents, the TA evaluated in the first session does not correlate with the results. This may be indicative of a stage of cautious exploration during which the adolescent does not clearly perceive what this process can achieve (goals), what he/she must do to achieve it (tasks), and whether this is a reliable and safe place for $\mathrm{him} / \mathrm{her}$ (bond), all of which leads to a cautious evaluation of the TA. This may be a differential characteristic of the TA in adolescents, because in studies with adults, the correlation between the TA and outcomes has been found to be higher in the first session (Santibañez, Román \&Vinet, 2009). In the third session, the TA displays a significant difference compared with the initial TA. This result may be interpreted as indicating that, at this point, the adolescent has managed to solve his/her doubts about goals and tasks and to evaluate the bond created. The type of response to these doubts (the perception of the TA in this stage) will influence the outcome of the process. Here lies the importance of working actively and participatively during the initial sessions on the therapeutic objectives or goals, on the commitments or efforts to be made by the adolescent, and on a reliable and safe bond. This does not only involve the direct effect (Hoffart et al., 2012) of the TA on change, but also its indirect influence, because a positive TA can generate the conditions that make it possible to question and combat (Hoffart et al., 2012) the dysfunctional cognitive, affective, and behavioral representations in place, unquestionable in a less safe context, but which must be challenged for change to occur.

In the case of the therapists, the TA perceived in the first two sessions was correlated with the more immediate (intermediate) outcomes, but not with the final outcomes. In turn, the TA of the first session, at least the therapeutic bond dimension, was correlated with the final outcomes.

These findings may indicate that the therapist, in the first two sessions, is able to perceive the TA as an indicator of permeability to changes in the patient. Meanwhile, his/her perception of the bond aspect of the TA in the third session can predict the success condition of the therapy, establishing the difference between successful and unsuccessful therapies. If the therapist observes a high-quality bond, he/she may consider that a sufficient level of trust has been achieved to engage in the questioning and the transformations required for a good outcome (indirect action of the TA). But the interpretation could also be that the therapist feels self-efficacious, empowered, and satisfied with his/her ability to generate a positive bond, and that this creates positive feedback that allows him/her to work in closer connection with the process and to pay more attention to the adolescent's needs, which may lead to a better outcome. If the therapist perceives a weak bond, it may be a sign that it is necessary to work urgently on this aspect of the relationship for the process to be successful (direct action of the TA). The perception of a weak bond with the adolescent patient may also influence the therapy indirectly by fostering feelings of devaluation in the therapist about the effectiveness of his/her professional work, which can generate a lack of motivation in connection with the process or direct his/her attention to his/her own professional performance and away from the patient. In conclusion, there is still much to investigate in order to fully understand the connection between the early alliance and outcomes.

With respect to developmental considerations, it has been mentioned how complex it is to establish the TA in an age group that generally receives therapy without awareness of the problem, is referred by others, and whose developmental needs may be at odds with the establishment of a helping relationship with an adult (Kazdin, 2004). Without wanting to deny this, it is also necessary to bear in mind that adolescence as an evolutionary stage weakens/destabilizes the experience of the self, with the main task of adolescents being to reorganize themselves by integrating the past and their new acquisitions into an identity that allows them to project themselves into the future (Aberastury \& Knobel, 1977; Blos, 1979; Quiroga, 1999). In this context marked by emotional instability and the need to attain unification, the TA with an adult-therapist can be a great source of support, 
either direct or indirect. Acting directly, the TA generates a space of support, acceptance, and validation of oneself and fosters active participation in the construction of goals and the definition of tasks in therapeutic space. Acting indirectly, the TA makes it possible to experience close bonds with an individual other than parents or family and to progress towards autonomy and differentiation, the central task during this phase of development. In addition, in this context it is more feasible to question and discover problematic or painful aspects of the self and to incorporate the new perspectives acquired, all of which are necessary tasks for attaining a favorable outcome.

Some of the limitations of the study result from the methodological challenge of examining therapeutic processes in naturalistic contexts, which make it difficult to include large numbers of participants and full therapeutic processes.

In addition, in naturalistic settings, male adolescents are underrepresented, because this reflects the natural distribution of the population receiving care at the health centers where the samples are collected.

\section{Conclusions}

Considering the relatively small sample size used, the negative results obtained - that is, those which indicate that no significant differences or associations exist between the variables studied - are inconclusive and leading to future studies with larger sample sizes.

\section{References}

Aberastury, A., \& Knobel, M. (1977). El sindrome de la adolescencia normal. Un enfoque psicoanalítico. Buenos Aires: Paidós.

Alberti, G., Martorano, A., \& Martorano, B. (2013). The competing influences of initial depressive symptomatology and early alliance on early outcome: A preliminary study. Research in Psychotherapy: Psychopathology, Process and Outcome, 16(2), 109-118.

Baruch, G., Gerber, A., \& Fearon, P. (1998). Adolescents who drop out of psychotherapy at a community-based psychotherapy centre: a preliminary investigation of the characteristics of early drop-outs, late drop-outs and those who continue treatment. British Journal of Medical Psychology, $71(3), 233-245$.

Bickman, L., de Andradre, A., Lambert, E., Doucette, A., Sapyta, J., \& Boyd, A. (2004). Youth therapeutic alliance in intensive treatment settings. Journal of Behavioral Health Services and Research, 31(2), 134-148.

Blos, P. (1979). La transición adolescente. Buenos Aires: Amorrortu.

Bordin, E. (1976). The generalizability of the psychoanalytic concept of the working alliance. Psychotherapy: Theory, Research, and Practice, 16(3), 252-260.

Bronstein, C., \& Flanders, S. (1998). The development of a therapeutic space in first contact with adolescents. Journal of Child Psychotherapy, 24(1), 5-35.
Coll, C., Palacios, J., \& Marchesi, A. (2004). Desarrollo psicológico y educación. Madrid: Alianza.

Corbella, S., \& Botella, L. (2003). La alianza terapéutica: historia, investigación y evaluación [Electronic version]. Revista Anales de Psicología, 2(19), 205-221.

De la Parra, G., von Bergen, A., \& del Río, M. (2002). Primeros Hallazgos de la Apñicación de un instrumento que mide resultados Psicoterapéuticos en una muestra de pacientes y de población general. Revista Chilena de Neuropsiquiatría, 40(3), 201-209.

Diamond, G., Diamond, G., \& Liddle, H. (2000). The therapist. Parent alliance in family-based therapy for adolescents. Psychotherapy in Practice, 56(8), 1037-1050.

Fenton, L., Cecero, J., Nich, C., Frankforter, T., \& Carroll, K. (2001). Perspective is everything: The predictive validity of six working alliance instruments. Journal of Psychotherapy Practice and Research, 10(4), 262-268.

Green, J. (2006). Annotation: the therapeutic alliance. A significant but neglected variable in child mental health treatment studies. Journal of Child Psychology and Psychiatry 47(5), 425-435.

Hill, C. (2005). Therapist techniques, client involvement, and the therapeutic relationship: Inextricably intertwined in the therapy process. Psychotherapy: Theory, Research, Practice, Training, 42(4), 431-442.

Hoffart, A., Borge, F.-M., Sexton, H., Clark, D., \& Wampold, B. (2012). Psychotherapy for social phobia: How do alliance and cognitive process interact to produce outcome? Psychotherapy Research, 22(1), 82-94.

Horvath, A., \& Greenberg, L. (1986). The development of the Working Alliance Inventary. In L.S. Greenberg \& W.M. Pinsof (Eds.), The psychotherapeutic process: A research handbook (pp 529-556). New York: Guilford.

Horvath, A.O., Del Re, A.C., Flückiger, C., \& Symonds, D. (2011). Alliance in individual psychotherapy. Psychotherapy, 48(1), 9-16. doi: 10.1037/a0022186.

Horvath, A.O., \& Symonds, B.D. (1991). Relation between working alliance and outcome in psychotherapy: A metaanalysis. Journal of Counseling Psychology, 38(2), 139-149.

Howard, K.L., Lueger, R.J., Maling, M.S., Martinovich, Z. (1993). A phase model of psychotherapy outcome: causal mediation of change. Journal of Consulting and Clinical Psychology, 61(4), 678-685.

Karver, M., Shirk, S., Handelsman, J., Fields, S., Crisp, H., Gudmundsen, G., \& McMakin, D. (2008). Relationship processes in youth psychotherapy. Measuring alliance, alliance-building behavoirs, and client involvement. Journal of Emotional and Behavioral Disorders, 16(1), 15-28.

Kazdin, A. (1990). Premature termination from treatment among children referred for antisocial behavior. Journal of Child Psychology and Psychiatry and Allied Disciplines, 31(3), 415-425.

Kazdin, A. (2004). Psychotherapy for children and adolescents. In W.J. Lambert (Ed.) Bergin and Garfield's handbook of psychotherapy and behavior change (pp. 543-589). New York: Wiley and Sons.

Krause, M. (2005). Psicoterapia y Cambio Una mirada desde la subjetividad. Santiago: Ediciones Universidad Católica de Chile.

Lambert, M.J. (1992). Implications of psychotherapy outcome research for eclectic and integrative psychotherapies. In: J.C. Norcross \& M.R. Goldfried (Eds.) Handbook of psychotherapy integration (pp. 94-129). New York: Basic Book. 
Lambert, M.J., \& Barley, D.E. (2002). Research summary on the therapeutic relationship and psychotherapy outcomes. In: J.C. Norcross (Ed.) Psychotherapy relationships that work: therapist contributions and responsiveness to patient needs (pp. 17-32). New York: Oxford University Press.

Lambert, M.J., Hansen, N.B., Umpress, V., Lunnen, K., Okiishi, J., \& Burlingame, G.M. (1996). Administration and scoring manual for the $O Q-45.2$. Wilmington, DE: American Professional Credentialing Services.

Manríquez, H., Molina, H., \& Zubarew, T. (2003). Promoción y prevención de salud en la adolescencia. In T. Zubarew, M. Romero \& F. Poblete (Eds.), Adolescencia, promoción, prevención y atención de salud. Santiago: Ediciones Universidad Católica de Chile.

Martin, D., Garske, J., \& Davies, M. (2000). Relation of therapeutic alliance with outcome and other variables: A metaanalytic review. Journal of Consulting and Clinical Psychology, 68(3), 438-450.

Martin, J., Romas, M., Medford, M., Leffert, N., \& Hatcher, S.L. (2006). Adult helping qualities preferred by adolescents. Adolescence, 41(161), 127-140.

Martínez, V., Martínez, P., Poblete, C., Chang, M., Brand, L., \& Soto, P. (2009). Psicoterapia para adolescentes en programa GES de depresión de un centro privado de salud mental. Revista Chilena de Psiquiatría y Neurología de la Infancia y Adolescencia, 19, 71-72.

Meier, P., Barrowclough, C., \& Donmall, M. (2005). The role of the therapeutic alliance in the treatment of substance misuse: A critical review of the literature. Addiction, 100(3), 304-316.

Oddli, H.W., \& Halvorsen, M.S. (2014). Experienced psychotherapists' reports of their assessments, predictions, and decision making in the early phase of psychotherapy. Psychotherapy, 51(2), 295-307. doi: 10.1037/a0029843

Oddli, H.W., \& Rønnestad, M.H. (2012). How experienced therapists introduce the technical aspects in the initial alliance formation: Powerful decision makers supporting clients' agency. Psychotherapy Research, 22(2), 176-193. doi: 10.1080/10503307.2011.633280

Oetzel, K.B., \& Scherer, D.G. (2003). Therapeutic engagement with adolescents in psychotherapy. Psychotherapy: Theory, Research, Practice, Training, 40(3), 215-225.

O’Malley, S., Such, C., \& Strupp, H. (1983). The Vanderbilt Psychotherapy Process Scale: A report on the scale development and a process-outcome study. Journal of Consulting and Clinical Psychology, 51(4), 581-586.

Orlinsky, D., \& Howard, K.J. (1986). Process and outcome in psychotherapy. In S.L. Garfield \& A.E. Bergin (Eds.), Hand- book of psychotherapy and behavior change (pp. 311-384). New York: Wiley.

Orlinsky, D., Ronnestad, M., \& Willutzky, U. (2004). Fifty years of process-outcome research in psychotherapy: Continuity and change. In M. Lambert (Ed.) Psychotherapy and Behavior Change (pp 307-389). New York: John Willey and Sons.

Prochaska, J., \& DiClemente, C. (1983). Stages and processes of self-change of smoking: Toward an integrative model of change. Journal of Consulting and Clinical Psychology, 51(3), 390-395.

Quiroga, S. (1999). Adolescencia: del goce orgánico al hallazgo del objeto. Buenos Aires: Eudeba.

Russell, R. (2008). Child and adolescent psychotherapy: Introduction to the special section. Psychotherapy Research, 18(1), 1-4.

Russell, R., Shirk, S., \& Jungbluth, N. (2008). First-session pathways to the working alliance in cognitive behavioral therapy for adolescent depression. Psychotherapy Research, 18(1), 15-27.

Santibáñez, P. (2001). La alianza terapéutica en psicoterapia. traducción, adaptación y examen inicial de las propiedades psicométricas del Working Alliance Inventory en Chile. Tesis para optar al grado de Magíster en Psicología Clínica, Pontificia Universidad Católica de Chile.

Santibáñez, P. (2002). La Alianza en Psicoterapia: Una sistematización. Terapia Psicológica, 20(1), 9-21.

Santibañez, P., Román, M.F., \& Vinet, E. (2009). Efectividad de la psicoterapia y su relación con la alianza terapéutica. Interdisciplinaria, 26(2), 267-287.

Scheffler, G. (2002). Psicoterapia de tiempo limitado. Jerusalem: University of Jerusalem.

Shelef, K., Diamond, G., Diamond, G., \& Liddle, H. (2005). Adolescent and parent alliance and treatment outcome in multidimensional family therapy. Journal of Consulting and Clinical Psychology, 73(4), 689-698.

Shirk, S., \& Karver, M. (2003). Prediction of treatment outcome from relationship variables in child and adolescent therapy: A metanalytic review. Journal of Consulting and Clinical Psychology. 71(3), 452-464.

Thompson, S.J., Bender, K., Lantry, J., \& Flynn, P.M. (2007). Treatment engagement: building therapeutic alliance in home-based treatment with adolescents and their families. Contemporary Family Therapy, 29(1-2), 39-55. doi: 10.1007/s10591-007-9030-6

Von Bergen, A. (2000). Investigación empírica en psicoterapia: Validación del cuestionario de resultados Terapéuticos $O Q-$ 45.2. Tesis para optar al grado de Magister, Universidad Andrés Bello, Santiago, Chile. 